\title{
UM ENSAIO SOBRE A INEFICÁCIA DA POLÍTICA PÚBLICA VINCULADA AO MICROEMPREENDEDOR INDIVIDUAL [MEI]
}

\author{
AN ESSAY ON THE INEFFICACY OF THE PUBLIC POLICY RELATED TO THE \\ INDIVIDUAL MICROENTREPRENEUR [MEI]
}

Recebido em 04.06.2019 Aprovado em 10.12.2019

Avaliado pelo sistema double blind review

Irene Ciccarino MsC.

DOI: https://doi.org/10.32888/cge.v7i2.28966

ireneciccarino@gmail.com

Programa de Doutorado em Administração/ PUC Rio - IAG - Rio de Janeiro/Rio de Janeiro, Brasil

Ana Moraes PhD.

ana.moraes@ibmec.edu.br

Programa de Mestrado Profissional em Administração/Faculdades Ibmec-Rio de Janeiro/Rio de Janeiro, Brasil

Ana Celano PhD.

ana.teixeira@ibmec.edu.br

Programa de Mestrado Profissional em Administração/Faculdades Ibmec-Rio de janeiro/Rio de Janeiro, Brasil

\section{Resumo}

O Microempreendedor individual - MEI - permite uma faixa de tributação mais baixa e um processo mais simples de cadastro online para formalização de negócios. Basicamente, espera-se que dois efeitos sejam percebidos: estimular o microempreendedorismo e estimular a formalização do trabalho. Sua divulgação é baseada na construção de uma linguagem positiva a partir da subjetividade do tema empreendedorismo - o herói, aquele que subiu na vida, enfatizando apenas os benefícios dessa formalização. Este ensaio teórico analisa os aspectos socioeconômicos e trabalhistas do MEI, como política pública, promovendo uma discussão crítica sobre o aparentemente inofensivo incentivo à formalização do trabalhador autônomo. A figura do MEI está mais próxima de uma mercantilização do trabalho do que de uma política de assistência social ou de desenvolvimento econômico. Para se enquadrar na primeira, deveria prover uma resposta às necessidades humanas de forma integral, de maneira preventiva e protetiva. No entanto, cria um processo de individualização da responsabilidade pelo desemprego, que ao deixar de ser uma questão coletiva e complexa, desobriga governo e a sociedade de tratá-la. Seu único efeito é basicamente laboral, sem grande expressividade na geração de novos postos de trabalho.

Palavras-chave: Microempreendedor individual. Empreendedorismo. Política pública.

\begin{abstract}
The individual microentrepreneur - MEI - allows a lower tax range and a simpler online registration process for business formalization. Basically, two effects are expected to be perceived: to stimulate microentrepreneurship and to stimulate the formalization of work. Its dissemination is based on the construction of a positive language based on the subjectivity of the theme entrepreneurship - the hero, the one who came from below and rose in life, emphasizing only the benefits of this formalization. This theoretical essay analyzes the socioeconomic and labor aspects of the MEI, as a public policy, promoting a critical discussion about the seemingly harmless incentive to the formalization of the autonomous worker. The MEI figure is closer to a commodification of labor than to a policy of social assistance or economic development. To fit the first, it should provide a comprehensive response to human needs, in a preventive and protective way. However, it creates a process of individualization of responsibility for unemployment, which ceases to be a collective and complex issue, releases government and society from treating it. Its only effect is basically labor, without great expressiveness in the generation of new jobs.
\end{abstract}

Keywords: Individual microentrepreneur. Entrepreneurship. Public policy. 


\section{Introdução}

A Lei Complementar $n^{\circ}$ 128/08 de 19 de dezembro de 2008 instituiu a figura jurídica do MEI em uma faixa de tributação mais baixa e simplificada, como um desdobramento da Rede Nacional para a Simplificação do Registro e da Legalização de Empresas e Negócios - REDESIM. A REDESIM foi criada através da Lei n ${ }^{\circ} 11.598 / 2007$, com o objetivo de gerenciar, por meio de um comitê, normas gerais para a simplificação e integração do processo de registro e legalização de empresários e de pessoas jurídicas (Portal do Empreendedor - MEI, recuperado em 09/04/2018).

Esforços anteriores já haviam sido realizados por meio da instituição do Sistema Integrado de Pagamento de Impostos e Contribuições das Microempresas e das Empresas de Pequeno Porte [Simples], em 1996, com o objetivo de reduzir os encargos burocráticos e tributários que incidem sobre as micro e pequenas empresas (Corseuil, Neri, \& Ulyssea, 2014).

A partir da criação desta lei, passa supostamente a existir um processo mais simples de cadastro online para o cidadão enquadrado em determinadas atividades, com receita de até 81 mil reais anuais e com até 1 (um) funcionário que ganhe o piso mínimo de sua função. Em poucos minutos, tem-se acesso ao Cadastro Nacional de Pessoa Jurídica [CNPJ] que permite, entre outros procedimentos, emitir notas fiscais e ter acesso às linhas de crédito destinadas as empresas (SEBRAE, 2018).

O MEI foi instituído para gerar dois efeitos: 1) estimular o microempreendedorismo e 2) estimular a formalização dos empreendedores individuais (Corseuil, Neri, \& Ulyssea, 2014). Sua divulgação é baseada na construção de uma linguagem positiva a partir da subjetividade do tema empreendedorismo - o herói, o selfmade man, aquele que veio de baixo e subiu na vida - e da ideia do brasileiro ser "naturalmente empreendedor" enfatizando apenas os benefícios dessa formalização (Salgado, 2012).

Este ensaio teórico tem o objetivo analisar a figura jurídica do Microempreendedor Individual [MEI], evidenciando seus aspectos socioeconômicos e trabalhistas, de maneira a produzir um diálogo entre o que deveria acontecer e o seu resultado prático, considerando a teoria levantada no referencial como parâmetro. Nesse sentido, o método ensaio teórico foi escolhido por permitir estabelecer comparações dialógicas sobre o tema ao longo do percurso (Meneghetti, 2011). A pretensão é que o tema estudado possa contrapor, passo a passo, as questões práticas do MEI enquanto política pública sob a perspectiva da teoria do empreendedorismo.

Ainda cabe salientar que este ensaio pretende se apresentar como uma discussão crítica do fenômeno do empreendedorismo em avenida de pesquisa já aberta por diversos autores (Costa \& Saraiva, 2012; Costa, Barros, \& Carvalho, 2011) e que supera o paradigma funcionalista vigente na academia. Tratase, então, de uma proposta de reflexão e não uma busca por relações de causa e efeito (Sette, Boava, \& Macedo, 2012). Desse modo, o estudo assume um caráter interpretativo, utilizando a abordagem qualitativa e exploratória para apresentar uma visão geral e aproximada do fenômeno discutido (Gil, 2008).

A relevância do trabalho reside no aparentemente inofensivo incentivo à formalização do trabalhador autônomo, que, se observado criticamente, parece um processo de transferência de responsabilidade do Estado pelo acesso ao mercado de trabalho (Salgado, 2012). Essa formalização, à primeira vista positiva, não chega a gerar efeitos diretos na atividade empreendedora do país, na arrecadação de impostos evadidos pela informalidade, na geração de emprego e renda, ou na melhoria do acesso do empreendedor à diretos ou serviços públicos ou privados (Bacha, 2017; Corseuil, Neri, \& Ulyssea, 2014; Salgado, 2012).

A própria figura do Microempreendedor individual é pouco pesquisada, carecendo de interesse acadêmico para que seja melhor compreendida e para que adequações possam ser demandadas. Ao se pesquisar a palavra-chave "Microempreendedor Individual" no EBSCOhost, foi possível recuperar 32 documentos científicos, provenientes de diversas bases de dados, publicados entre os anos de 2010 e 2017 (BASE, RCAAP, Directory of Open Access Journals, Academic OneFile, Networked Digital Library of Theses \& Dissertations, Academic Search Complete, Business Source Complete, Computers \& Applied Sciences Complete, Fuente Académica Premier, Complementary Index, 
SciELO, General OneFile). Desses, 26 eram dissertações ou teses, 2 falavam de aspectos da percepção dos MEI, 2 de direito e tributação, 2 eram estudos de caso (recuperado em 09/04/2018). Pesquisando mais profundamente foi possível identificar mais 2 artigos que endereçam aspectos da política pública e compuserem o referencial teórico deste trabalho. A figura jurídica do Microempreendedor Individual torna-se expressivamente pouco pesquisada em comparação com os 9329 estudos sobre empreendedorismo (75 só no Brasil) ou 1732 sobre políticas públicas (329 só no Brasil) produzidos no mesmo período.

A contribuição teórica deste artigo está em levantar informações sobre o MEI e os efeitos dessa política na sociedade, na economia fundamentalmente quando comparado a atividade empreendedora. Também evidencia a importância de se observar a teoria na construção de políticas públicas para que seus resultados sejam eficazes. Sua contribuição prática está na análise crítica de uma política pública o que gera uma oportunidade para ajustes e melhorias futuras.

\section{O contexto da política pública}

Mackey e Sisodia, (2013) defendem que o capitalismo se perdeu no momento em que o pensamento neoliberal concentrou o propósito das empresas na geração de lucro desviando-o da geração de valor social. Dentro deste contexto, certa desigualdade parece inevitável. Entretanto, a forma extrema da desigualdade vista hoje, em nível mundial, pode ser pareada a uma disfunção do capitalismo (Santos, 2002). A desigualdade da distribuição de renda é negativamente relacionada ao nível de industrialização, pois restringe o tamanho do mercado. Embora haja a necessidade de uma classe média que sustente o crescimento da economia (Santos, 2002 Chowdhury, 2013), quanto mais desigual é a sociedade, menos a economia cresce em longo prazo (Piketty, 2015; Stiglitz, 2012). Tal disfunção tende a agravar situações históricas de desigualdade social, como as vivenciadas no Brasil e na América Latina (Ibarra-Colado, 2006; Wanderley \& Barros, 2018).

A partir dessa perspectiva, deve-se observar que há uma grande tendência de se acreditar que os investimentos sociais são apenas custos, fardos para atenuar vulnerabilidades sociais críticas. As políticas públicas acabam sendo dimensionadas pelas políticas econômicas sofrendo mais ou menos investimentos de acordo com o cenário. Essa limitação de escopo é semelhante a admitir que os problemas sociais sejam efeitos residuais que poderiam ser aliviados com ações isoladas, embora tais problemas sejam endêmicos das malhas sociais em que se manifestam (Soares, 2015; Souza, 2009; Santos, 2002).

A desigualdade social não é fruto da pobreza econômica, mas sim de uma insuficiência produtiva para incorporar às necessidades básicas de todos os indivíduos (Caetano, 2015). Essa desigualdade reduz o crescimento e a eficiência econômica, pois atinge o capital humano disponível em uma sociedade, afetando fortemente o mercado de trabalho (Stiglitz, 2012; OCDE, 2018). A concentração de poder econômico nas mãos de poucos alimenta essa desigualdade à medida que o coletivo é pressionado pelos interesses privados, direcionando recursos para certas áreas em detrimento de outras. As áreas que mais são impactadas, em geral, são as que criariam a estrutura para o crescimento da economia como um todo, por exemplo: educação e tecnologia (Stiglitz, 2012). Um exemplo disso são as recentes políticas de transferência de renda no Brasil (Solano, 2015): o investimento em capital humano realizado pelo incentivo a educação - Bolsa Família, ProUni, PRONASCI, etc - não encontra na economia postos de trabalho que façam o progresso acontecer (Stiglitz, 2012). Uma alternativa para potencializar essa criação de postos de trabalho pode ser o incentivo à atividade empreendedora (Ács, Szerb, Autio, \& Lloyd, 2018; Herrington \& Kew, 2016). A seguir a política pública do MEI será discutida sob as óticas social e empreendedora, desdobrando o argumento apresentando nesta breve contextualização. 


\section{O MEI em relação as políticas e públicas de assistência social no brasil}

No Brasil, a partir de 2004, foi instituído o Sistema Único de Assistência Social [SUAS] por meio da implantação da Política Nacional de Assistência Social como aparato estatal para planejamento e execução de programas e serviços (BRASIL MDS, 2005). O SUAS orienta à criação de respostas às necessidades humanas de forma integral, de maneira preventiva e protetiva. Os serviços, projetos, programas e benefícios sócio assistenciais têm como foco prioritário a atenção às famílias e seus membros. Os territórios são as bases de organização, que passam a ser definidos pelas funções que desempenham, pelo número de pessoas que deles necessitam e pela sua complexidade.

Um dos conceitos trabalhados por essa política é a autonomia que pode ser traduzida como o processo que constitui a capacidade dos sujeitos de "compreenderem e agirem sobre si mesmos e sobre o contexto, conforme objetivos democraticamente estabelecidos” (BRASIL, 2013, p. 69). Isso significa que ações de atendimento vêm sendo ampliadas, incorporando mecanismos prioritários, como acessos aos serviços públicos e inserção produtiva, de forma a fomentar o alcance de famílias e indivíduos extremamente pobres, mas dentro de um enfoque multidimensional de pobreza (Santana, 2016).

Cabe observar que, em sua essência, uma política pública representa um "conjunto de sucessivas iniciativas, decisões e ações do regime político frente a situações socialmente problemáticas e que buscam a resolução delas, ou pelo menos trazê-las a níveis manejáveis" (Bucci, 2006, p. 43).

No entanto, a maioria das políticas públicas no Brasil ainda segue o ponto de vista de uma classe privilegiada para tratar de questões das camadas mais baixas da sociedade originando a chamada "má fé institucional” (Souza, 2009). As trajetórias de vida das camadas mais vulneráveis e as construções que se formam por meio da falta de acessos limitam o desenvolvimento de repertórios mais amplos. Essa dissonância muitas vezes impede que as oportunidades oferecidas a esses indivíduos, mesmo que criadas de forma incorreta, sejam aproveitadas da forma que foram idealizadas. Desse modo, a oferta não gera uma mudança efetiva, por não se adequar a capacidade de o indivíduo perceber e aproveitar oportunidades, o que gera frustrações de ambos os lados.

Por meio dessa reflexão pode-se esperar que o MEI seja mais uma política de exceção. No entanto, para além de ser uma política pública ele também busca desenvolver o empreendedorismo, o que, naturalmente traria impactos econômicos. O Quadro 1 resume os aspectos da política de assistência social destacadas em comparação com o potencial do MEI em atendê-la.

Quadro 1 - Elementos da política de assistência social brasileira

\begin{tabular}{|c|c|}
\hline Elementos do contexto Brasileiro & $\begin{array}{l}\text { Onde o MEI se propõe a atuar } \\
\text { enquanto política pública }\end{array}$ \\
\hline Resposta integral às necessidades humanas (BRASIL MDS, 2005; Soares, 2015) & \multirow{10}{*}{$\begin{array}{l}\text { Não faz parte do propósito da } \\
\text { política nem há indícios de que } \\
\text { esses elementos sejam } \\
\text { observados nos parceiros. }\end{array}$} \\
\hline Atuação preventiva (BRASIL MDS, 2005) & \\
\hline Atuação protetiva (BRASIL MDS, 2005) & \\
\hline Atenção às famílias (BRASIL MDS, 2005) & \\
\hline Desenvolvimento de autonomia (BRASIL, 2013) & \\
\hline Adoção do ponto de visto do beneficiário (Souza, 2009) & \\
\hline Atuação sobre as causas da questão e não sobre suas consequências (Soares, 2015) & \\
\hline Melhoria dos serviços públicos ofertados (Albarce, 2015) & \\
\hline $\begin{array}{l}\text { Aumento da atuação dos cidadãos fiscalizando, usufruindo e demandando suas } \\
\text { questões (Santos, 2002) }\end{array}$ & \\
\hline $\begin{array}{l}\text { Alívio da pobreza por meio de acessos prioritários aos serviços públicos (BRASIL, } \\
\text { 2013; Santana, 2016) }\end{array}$ & \\
\hline $\begin{array}{l}\text { Alívio da pobreza por meio de acessos mecanismos de inserção produtiva } \\
\text { (BRASIL, 2013; Santana, 2016) }\end{array}$ & $\begin{array}{l}\text { O MEI pode ser uma alternativa } \\
\text { de inserção produtiva, no } \\
\text { entanto, muito vinculada a } \\
\text { dificuldade de inserção no } \\
\text { mercado formal de emprego. }\end{array}$ \\
\hline
\end{tabular}

\section{Legenda:}

\section{+ Positivo}

\section{- Negativo}

Fonte: Elaborado pelos autores. 
De acordo com Sarfati (2013), no caso dos MEIs, existe um ponto a ser esclarecido sobre a necessidade e escopo de políticas públicas específicas. Seria necessário diferenciar políticas públicas deste tipo de empreendedorismo de políticas públicas para as MPMEs, já que as voltadas para as MPMEs envolvem programas que apoiam o estilo de vida empreendedor, o que pode ser justificado por diversas razões, como efeitos macroeconômicos positivos de criação de empregos ou mesmo compensação por efeitos microeconômicos. Isso nos leva ao objetivo do MEI, ou seja: em desenvolver o empreendedorismo que será discutido na próxima seção (Corseuil, Neri, \& Ulyssea, 2014; Salgado, 2012).

\section{O MEI e o empreendedorismo}

Pode-se dizer que o empreendedorismo seja um processo por meio do qual uma ideia é colocada em prática de maneira economicamente viável e lucrativa, tornando-se um negócio com visão de longo prazo por meio da identificação, avaliação e exploração de oportunidades (Baron \& Shane, 2006; Shane \& Venkataraman, 2000).

Nos últimos anos, observou-se um aumento da popularidade do tema empreendedorismo, possivelmente devido aos recorrentes e prolongados períodos de crise econômica mundial. $\mathrm{O}$ empreendedorismo aparece no cenário como uma grande esperança por representar o estudo da criação de novas empresas, embora não se limite apenas a isso (Ferreira et al., 2014; Shane, 2012; Zouain, Oliveira, \& Barone, 2007; Costa, Barros, \& Carvalho, 2011).

O relatório do GEDI - Global Entrepreneurship Development Institute (Ács et al., 2018) sinaliza a importância do empreendedorismo na geração de postos de trabalho e circulação de renda, alertando contra as altas taxas de desemprego, que representam a escalada da violência, principalmente para os jovens. Essa perspectiva leva diversos governos a estimularem ações empreendedoras, que tendem a ser mais efetivas quando viabilizam a criação de um ecossistema empreendedor (Arruda et al., 2013; Simatupang \& Schwab, 2015; Herrington \& Kew, 2016; Ács et al., 2018).

Um ecossistema empreendedor é um construto complexo e multinível que busca explicar a rede de relações, interdependências e sinergias em um ambiente empreendedor. São as condições individuais, sociais, governamentais e de mercado que possibilitam o desenvolvimento da atividade empreendedora em determinado local. A premissa é a de que empreendedores obtêm maior êxito quando encontram um ambiente propício para as suas atividades e, portanto, passa a ser fundamental criar um ambiente favorável aos negócios, principalmente os novos negócios, que correm maior risco de não lograr êxito nos primeiros anos de sua existência. Essa preocupação nasce a partir da 1) constatação das inúmeras partes interessadas envolvidas nesse processo, 2) do reconhecimento de que existem trocas tanto de recursos quanto de conhecimento entre empresas e sociedade, 3) da necessidade de políticas integradas que agreguem infraestrutura, facilitem o processo empreendedor e promovam inovação, produtividade, criação de postos de trabalho e crescimento econômico. Essa dinâmica eleva a renda e o capital humano local, atrai talentos e gera mais negócios em um ciclo virtuoso (Simatupang \& Schwab, 2015).

A OCDE (2018) propõe seis domínios para a construção de um ecossistema empreendedor: 1) Políticas Públicas; 2) Capital financeiro; 3) Cultura; 4) Instituições de Suporte; 5) Recursos humanos; 6) Mercado.

O GEDI propõe 14 pilares para análise de um ecossistema empreendedor:1) Percepção de oportunidades; 2) Habilidades empresariais; 3) Tolerância aos riscos; 4) Redes (networking); 5) Cultura empreendedora; 6) Oportunidades para empresas; 7) Tecnologia; 8) Capital humano; 9) Competição; 10) Inovação em produtos; 11) Inovação em Processos; 12) Empresas de alto crescimento; 13) Internacionalização; 14) Capital de Risco. O Brasil está abaixo da média mundial em 11 pilares e abaixo da média da América Latina em 5, ocupando a 98ª posição em um ranking de 137 países (Ács et al., 2018). 
As políticas públicas de promoção do empreendedorismo, em geral, apresentam três enfoques: 1) atração de novos negócios para a localidade; 2) encorajamento da criação de startups (negócios de rápido crescimento, em geral no campo da inovação e tecnologia); 3) promoção da expansão e estabilidade dos negócios existentes. A atração de novos negócios é limitada às características locais como demografia, proximidade de grandes mercados consumidores, facilidades logísticas, incentivos tributários, mãos de obra, etc. O encorajamento à criação de startups é altamente arriscado, pois essas empresas nem sempre amadurecem ao ponto de gerar empregos (Summers, 2015). Principalmente se for levada em conta a taxa de mortalidade de empresas no Brasil: 23,4\% falem em até 2 anos de atividade (SEBRAE, 2016). Por fim, a forma mais interessante é concentrar os incentivos nas empresas que já apresentam algum tipo de crescimento e geram empregos, ainda que esse perfil de empresa seja o mais raro justamente devido à alta taxa de mortalidade das empresas (Summers, 2015). No Brasil, há uma forte tendência a trabalhar o empreendedorismo por meio da desburocratização e do acesso à informação. Como exemplos do primeiro temos o próprio MEI (2009) e o Simples Nacional (1996). O acesso à informação, embora seja uma forma efetiva de potencializar a atividade empreendedora (Cho \& Honorati, 2013), em geral acontece na expectativa de que o empreendedor busque e acesse os programas que a fornecem, como é o caso das informações fornecidas por meio do SEBRAE. As diferenças de acesso, principalmente a educação, podem limitar a procura desses serviços a uma parcela muito pequena de empreendedores capazes de valorizar sua utilização (Souza, 2009; Cho \& Honorati, 2013).

É difícil prever o potencial de retorno social sobre o investimento na atividade empreendedora, principalmente por ele ser de longo prazo (Summers, 2015; Simatupang \& Schwab, 2015; Cho \& Honorati, 2013). No entanto, o tipo de empreendedorismo incentivado pode ajudar a esclarecer o assunto. Tanto o GEDI quanto o GEM - Global Entrepreneurship Monitor - fazem distinção entre duas categorias de empreendedorismo. A primeira categoria é o empreendedorismo por necessidade, e refere-se aos pequenos empresários, empresas familiares e àqueles que não conseguem se incluir no mercado formal de trabalho - auto emprego, subemprego, etc. Essa categoria está negativamente correlacionada com crescimento econômico, liberdade econômica e competitividade. Quanto maior é a taxa de empreendedorismo inicial referente à essa categoria, pior a economia se encontra, por uma questão de sustentabilidade. A segunda categoria é o empreendedorismo por oportunidade onde a principal tônica é o sucesso comercial. Esse tipo de empreendedorismo apresenta alto crescimento, escalabilidade e bons níveis de planejamento de curto e longo prazo. Por isso, são menos afetados pelas regulações (taxas, burocracias, etc.) e tendem a gerar empresas mais longevas. Além disso, geram mais postos de trabalho, inovação e crescimento econômico (Ács et al., 2018; Herrington \& Kew, 2016).

Devido à representatividade das pequenas empresas e trabalhadores autônomos nas economias, as políticas públicas também se direcionam para a sua promoção (Herrington \& Kew, 2016). Porém, as rendas provenientes dessas atividades estão longe de serem satisfatórias para gerar alguma mudança no contexto de desigualdade e impactar com materialidade o crescimento da economia (Summers, 2015).

Nassif, Ghobril, e Amaral (2009) ressaltam, com base nos estudos clássicos de Keynes (1930), Schumpeter (1942) e Timmons (1989), que o empreendedorismo gera mais trabalho e riqueza em países industrializados. Também se observa que os empreendedores, por necessidade, têm menor expressividade na economia de um país devido à ausência de inovação e tecnologia de seus negócios, caracterizando um "retardamento no desenvolvimento econômico-social, ampliando a atividade informal e sem estrutura" (Nassif, Ghobril, \& Amaral, 2009). Para os autores, a atividade empreendedora brasileira é relacionada à dificuldade de entrada no mercado de trabalho, logo predominantemente voltada ao empreendedorismo por necessidade. Para encerrar esta seção o Quadro 2 resume os aspectos do empreendedorismo destacados em comparação com o potencial do MEI em atendê-los. 


\section{Quadro 2 - Elementos de um ecossistema empreendedor.}

\begin{tabular}{|c|c|}
\hline Elementos do empreendedorismo & $\begin{array}{l}\text { MEI como política de apoio ao Micro } \\
\text { empreendedorismo }\end{array}$ \\
\hline Formação de empresas (Ebrashi, 2013). & $\begin{array}{l}\text { A atuação de parceiros como o SEBRAE e de } \\
\text { empresas voltadas para esse público alvo podem } \\
\text { motivar novos empreendedores por meio da } \\
\text { educação e da exposição à ideia. }\end{array}$ \\
\hline Instituição formal de empresas. & Objetivo principal do MEI \\
\hline $\begin{array}{l}\text { Identificação, avaliação e exploração de oportunidades } \\
\text { (Shane \& Venkataraman, 2000; Baron \& Shane, 2006). }\end{array}$ & \multirow{7}{*}{$\begin{array}{l}\text { A educação empreendedora pode potencializar } \\
\text { essa capacidade, porém não há ligação direta nem } \\
\text { indícios de que gere esse efeito, principalmente se } \\
\text { levarmos em conta as limitações de } \\
\text { enquadramento do MEI. }\end{array}$} \\
\hline $\begin{array}{l}\text { Negócio economicamente viável e lucrativo (Baron \& } \\
\text { Shane, 2006). }\end{array}$ & \\
\hline $\begin{array}{l}\text { Negócio com visão de longo prazo (Baron \& Shane, } \\
\text { 2006). }\end{array}$ & \\
\hline Atenção aos modelos de negócio (Baron \& Shane, 2006). & \\
\hline $\begin{array}{l}\text { Processo de geração e apropriação de valor (Sarasvathy \& } \\
\text { Venkataraman, 2001). }\end{array}$ & \\
\hline $\begin{array}{l}\text { Política de educação empreendedora e acesso à } \\
\text { informação (Cho \& Honorati, 2013). }\end{array}$ & \\
\hline $\begin{array}{l}\text { Incentivo ao empreendedorismo por necessidade (Ács et } \\
\text { al., 2018; Herrington \& Kew, 2016). }\end{array}$ & \\
\hline $\begin{array}{l}\text { Incentivo ao empreendedorismo por oportunidade (Ács et } \\
\text { al., 2018; Herrington \& Kew, 2016; Nassif, Ghobril, \& } \\
\text { Amaral, 2009). }\end{array}$ & $\begin{array}{l}\text { As limitações de enquadramento do MEI não } \\
\text { favorecem esse tipo de empreendedorismo. }\end{array}$ \\
\hline Sustentabilidade do negócio. & $\begin{array}{l}\text { Em geral, as limitações de enquadramento do } \\
\text { MEI favorecem o empreendedorismo por } \\
\text { necessidade que é mais vulnerável à diversos } \\
\text { fatores econômicos e regulatórios. }\end{array}$ \\
\hline $\begin{array}{l}\text { Crescimento econômico, com metas em longo prazo } \\
\text { (Summers, 2015; Simatupang \& Schwab, 2015; Cho \& } \\
\text { Honorati, 2013). }\end{array}$ & $\begin{array}{l}\text { As limitações de enquadramento do MEI, } \\
\text { principalmente no que tange receita e quantidade } \\
\text { de empregados não geraria um crescimento } \\
\text { econômico direto. }\end{array}$ \\
\hline $\begin{array}{l}\text { Política com enfoque na atração de novos negócios para a } \\
\text { localidade (Summers, 2015). }\end{array}$ & \multirow{3}{*}{$\begin{array}{l}\text { Não faz parte do propósito da política nem há } \\
\text { indícios de que os parceiros esses elementos } \\
\text { sejam observados. }\end{array}$} \\
\hline $\begin{array}{l}\text { Política com enfoque no encorajamento da criação de } \\
\text { startups (negócios de rápido crescimento, em geral no } \\
\text { campo da inovação e tecnologia) (Summers, 2015). }\end{array}$ & \\
\hline $\begin{array}{l}\text { Política de promoção da expansão e estabilidade dos } \\
\text { negócios existentes (Summers, 2015). }\end{array}$ & \\
\hline $\begin{array}{l}\text { Políticas integradas para desenvolver o ecossistema } \\
\text { empreendedor - fatores elencados pela OCDE e GEDI - } \\
\text { (Ács et al., 2018; Simatupang \& Schwab, 2015; Arruda et } \\
\text { al., 2013). }\end{array}$ & $\begin{array}{l}\text { Embora apareça como meta em alguns discursos a } \\
\text { movimentação em torno do MEI gira em torno de } \\
\text { fomentar o micro empreendedorismo e não de } \\
\text { criar ou fortalecer um ecossistema empreendedor. }\end{array}$ \\
\hline $\begin{array}{l}\text { Aspectos do desenvolvimento de um ecossistema } \\
\text { empreendedor - fatores elencados pela OCDE e GEDI - } \\
\text { (Ács et al., 2018; Simatupang \& Schwab, 2015; Arruda et } \\
\text { al., 2013). }\end{array}$ & $\begin{array}{l}\text { A política vinculada ao MEI não atende } \\
\text { diretamente a nenhum aspecto do GEDI, mas visa } \\
\text { desenvolver os seguintes aspectos que podem } \\
\text { fazer parte de um ecossistema empreendedor } \\
\text { segundo a OCDE: 1) Educação e acesso a } \\
\text { informação; 2) Simplificação de burocracias e } \\
\text { diminuição de taxas; 3) Instituições de suporte. }\end{array}$ \\
\hline
\end{tabular}

\begin{tabular}{l|l|l|l} 
Legenda: & & & \\
+Positivo \\
Fonte: Elaborado pelos autores
\end{tabular}

Fonte: Elaborado pelos autores. 


\section{Análise dos efeitos do microempreendedor individual [MEI]}

Em 2009, a Lei Complementar no 128/08 entrou em vigor instituindo a figura jurídica do MEI em uma faixa de tributação mais baixa e simplificada. Sua divulgação baseou-se em um discurso de apelo à formalização relacionado ao acesso à benefícios sociais, como por exemplo à previdência, e benefícios de mercado como acesso ao crédito. O governo e seus parceiros, como o SEBRAE e empresas privadas que surgiram para atender a esse nicho, embasam seus discursos de apoio ao MEI em valores como simplicidade e rapidez, e reforçam a ideia de se tratar de uma iniciativa de apoio ao empreendedorismo (Portal do Empreendedor - MEI, recuperado em 18/03/2018).

Para Corseuil, Neri e Ulyssea (2014) os objetivos da política pública vinculada à figura jurídica do MEI são: 1) promover o micro empreendedorismo no Brasil; 2) facilitar e encorajar o processo de formalização de negócios. Para os autores, a política pública foi exitosa na promoção do micro empreendedorismo, principalmente por conta do acesso facilitado à previdência.

A pertinência da instituição do MEI é justificada pelo fato de que, segundo o IBGE, até 2011, 75\% dos empreendedores Brasileiros eram informais, isto é, não estavam inscritos no Cadastro Nacional de Pessoa Jurídica [CNPJ]. Além da evasão fiscal, essa informalidade muitas vezes vem acompanhada com a falta de contribuição previdenciária, entraves no fechamento de transações por impossibilidade de geração de notas fiscais e dificuldades de acesso ao crédito (Corseuil, Neri, \& Ulyssea, 2014).

Entre os anos de 2003 e 2008 houve ainda uma queda da participação de microempreendedores na taxa de ocupação de país, talvez em parte explicada pelo aquecimento do mercado de trabalho vivenciado até 2011. De certa forma, percebeu-se a sinalização de que eles estavam abandonando a atividade empreendedora para ingressarem no mercado formal de trabalho como empregados em outras empresas (Corseuil, Neri, \& Ulyssea, 2014).

Estes microempreendedores são importantes para o dinamismo econômico do país (IBGE, 2017; Maloney, 2004), embora outros autores defendam que essa expectativa é por vezes exagerada, havendo uma importância relativa a outros elementos que precisam ser considerados como nível de industrialização da economia, escala do negócio, potencial de geração de emprego e renda, capacidade de crescimento, sustentabilidade econômico-financeira, etc. (Ács et al., 2018; Summers, 2015; Chowdhury, 2013; Hayward et al., 2006; Salgado, 2012). Sagado (2012) publicou uma pesquisa baseada em análise de discurso sobre o MEI adotando a perspectiva do emprego. A autora alerta para construção de uma linguagem positiva a partir da subjetividade do tema empreendedorismo como o herói, o selfmade man, aquele que veio de baixo e subiu na vida, além da exploração da ideia do brasileiro ser naturalmente empreendedor (Zouain, Oliveira, \& Barone, 2007; Sarfati, 2013).

Mundialmente, as relações trabalhistas caminham para contratos psicológicos menos recíprocos, com laços tácitos e objetivos mais flexíveis (Cappelli, 1999) e as políticas sociais seguem a mesma tendência (Salgado, 2012). A economia passa a assumir o papel de mediação do trabalho das pessoas, enquanto os sistemas econômicos como o capitalismo apontam para um comportamento desprovido de equidade (Piketty, 2015; Albarce, 2015; Soares, 2015; Santos, 2002). Com a globalização, a responsabilidade pela empregabilidade é transferida para o indivíduo. Assim, o problema do desemprego deixa de ser coletivo para se tornar individual" em um processo de "desconstrução do desemprego" (Salgado, 2012, p. 3). Quando os indivíduos para realizarem auto emprego ou subempregos são taxados de empreendedores passam a assumir a responsabilidade por sua renda. Assim, o Estado se desobriga de prover ações referentes a criação de postos de trabalho ou melhorias na educação técnica, passando a oferecer pequenos auxílios para que indivíduos assumam responsabilidade de empresas (Salgado, 2012).

Os benefícios sinalizados para incentivar a formalização através do MEI escondem um risco pouco divulgado: ao aderir ao MEI o indivíduo perde o direito de receber auxílio desemprego. Mesmo que o MEI concilie a atividade de microempreendedor com alguma do mercado formal, ao perder a atividade formal, em tese, ainda será capaz de gerar renda. Desse modo é excluído da elegibilidade ao auxílio. 
Determina-se como pessoas ocupadas aquelas que exerceram trabalho, remunerado ou sem remuneração, durante pelo menos uma hora completa na semana de referência, ou que tinham trabalho remunerado do qual estavam temporariamente afastadas nessa semana (IBGE, 2007, p. 3). Essa ocupação pode acontecer se a pessoa for empregada formal, estiver em situação de auto emprego [conta própria], se for um empregador [empresário] ou trabalhador não remunerado em unidade domiciliar, como por exemplo, a figura da dona de casa. Considera-se ainda a figura do "desalentados": pessoas que procuraram trabalho ininterruptamente durante pelo menos seis meses, porém, desistiram. Pelo mesmo motivo do impedimento ao auxílio desemprego, a figura do MEI classifica pessoas como ocupadas, mesmo se não estiverem conseguindo gerar receita por meio de suas personalidades jurídicas. Essas pessoas não poderão aparecer como desocupadas ou desalentadas, pois possuem virtualmente os meios de gerar renda - auto emprego (Kon, 2012).

O Portal do Empreendedor - MEI apresenta algumas estatísticas sobre a evolução dos últimos 9 anos (http://www.portaldoempreendedor.gov.br, recuperado em 9/04/2018), longe da meta inicial de atingir os 11 milhões de brasileiros que atuam no mercado informal (Salgado, 2011). Dos 6.653.221 inscritos desde o início do programa, $56 \%$ da concentração de inscritos estão no eixo sul-sudeste. Desse modo, o resultado indica que a política em si está longe de ser capaz de superar as desigualdades sociais por meio da atividade econômica, reforçando antigos padrões nacionais (Barros, 2011).

Relacionando a questão social com a trabalhista, 22\% dos MEIs são jovens entre 15 e 29 anos. Essa concentração na população jovem, que deveria estar se qualificando e ingressando no mercado de trabalho para adquirir experiência prática, pode sinalizar problemas. Barros (2011) argumenta que a principal causa da desigualdade entre as regiões brasileiras é a diferença de capital humano concentrada em cada uma delas. $\mathrm{O}$ autor explica como a repercussão geográfica se origina de uma série de decisões familiares e oportunidades de acessos. Em suma, a família investe na educação dos filhos para que eles ocupem melhores espaços no mercado de trabalho gerando uma progressão geracional. O inverso também é real, reforçando o ciclo de reprodução da pobreza devido à limitação de recursos e acessos, a priorização do trabalho precoce e o baixo incentivo à educação formal (Gregorio \& Lee, 2002; Castello \& Domenech, 2002).

As perspectivas de emprego para os jovens e os trabalhadores pouco qualificados têm diminuído nos países acompanhados pela OCDE devido à crise econômica, trazendo consequências sociais que perdurarão por muitos anos. Os jovens brasileiros têm três vezes mais riscos de ficarem desempregados do que um adulto. Eles representam 46\% dos desempregados no país e atualmente compõem a maior parte da população (OCDE, 2015). Ao considerarmos que o Brasil é dos países que apresenta o maior retorno sobre anos de educação formal, essa relação desigual de oportunidades se torna crítica. Cada ano de estudo acrescenta em média 16\% a mais na renda (Neri \& Costa, 2002). Os jovens podem estar aderindo ao MEI devido à falta de capacitação, e se for isso, a deficiência de capital humano brasileira tenderá a se agravar (Barros, 2011).

Um relatório do SEBRAE (2017) demonstrou que a população economicamente ativa no Brasil estava dividida da seguinte forma: 49\% mercado formal de trabalho (incluindo servidor público e trabalhador doméstico), $4 \%$ empregadores, $23 \%$ auto emprego ou emprego familiar, $14 \%$ desocupados. Como um MEI pode ter apenas um funcionário contratado pelo salário mínimo ou piso da categoria (MTE, 2018), seria responsável por menos de 9\% dos empregos formais (SEBRAE, 2017). A baixa expressividade (9\%) alinhada às limitações, tanto do salário pago ao único funcionário contratado, quanto da receita anual,diminuem muito a expressividade econômico-social do programa, e sinalizam que a fonte de arrecadação de renda por meio da formalização possa ser o principal intuito do programa.

Corseuil, Neri e Ulyssea (2014) descobriram que um indivíduo em situação de auto emprego passou a ter $67 \%$ a mais de chance de se formalizar, e um elemento motivador foi a contribuição previdenciária. Porém, foram identificadas evidências de que o crescimento dos cadastros como MEI sejam provenientes de empresários maiores reduzindo a escala para se enquadrarem nos limites do MEI. Nesse aspecto, nem o aumento da arrecadação seria um efeito direto da instituição da figura do 
MEI. Há evidências de que o MEI ainda seja um elemento da precarização do trabalho. Algumas empresas, em particular as menores, talvez estejam optando por contratar MEI para prestação de serviços outrora prestados por funcionários formalizados ou não. Os autores descobriram uma queda na chance de uma pessoa manter seu emprego formal é $37 \%$ em empresas com até cinco empregados, e de $24 \%$ com mais de cinco empregados. A situação de trabalho informal também se altera com a chance de manutenção caindo $32 \%$ em empresas com até cinco empregados e de $44 \%$ com mais de cinco empregados. Há indícios, inclusive, que algumas empresas incentivam seus colaboradores a se inscreverem como MEI para manterem suas relações laborais.

Talvez o programa melhorasse o desempenho econômico brasileiro de outras formas se pudesse contribuir mais efetivamente para o ecossistema empreendedor nacional. Para avaliar este ponto, incluiu-se na análise os dados do GEDI. No referido documento, o Brasil ocupa a $98^{\circ}$ posição de um ranking de 137 países, a $15^{a}$ posição em relação à 24 países da américa latina (Ács et al., 2018). Em comparação com o relatório de 2009, o país caiu 41 posições no ranking de empreendedorismo (Ács et al., 2009). A área mais fraca do país é a internacionalização, justamente seguida por capital humano, conforme já discutimos.

Embora o Brasil seja grande e diversificado, sua participação no mercado mundial, em grande parte, se dá apenas com produtos de baixo valor agregado provenientes da agricultura e mineração. Em contraste, o país é o sexto destino preferido para o investimento direto estrangeiro no mundo. Isso tem um efeito empobrecedor, pois as multinacionais prosperam ao explorar o mercado interno, enquanto as empresas nacionais permanecem com dificuldades para alcançar patamares de produtividade que as tornem competitivas no mercado internacional. Os motivos são vários, desde as barreiras às importações sem substituições internas interessantes, até a baixa taxa de investimento em capital fixo, especialmente em infraestrutura, e pesadas cargas tributárias. A questão do capital humano também é apontada como um elemento que prejudica a competitividade brasileira (Bacha, 2017).

\section{Considerações finais}

A figura do MEI está mais próxima de uma mercantilização do trabalho do que de uma política de assistência social ou de desenvolvimento econômico (Corseuil, Neri, \& Ulyssea, 2014; Salgado, 2012). Para se enquadrar na primeira, deveria prover uma resposta às necessidades humanas de forma integral, de maneira preventiva e protetora, o que não acontece ao generalizar o impedimento ao direito do auxílio desemprego, por exemplo (BRASIL MDS, 2005).

O trabalho de esclarecimento e apoio realizado pelo SEBRAE é o que mais aproxima a política pública do MEI com a assistência social no que se refere à geração de autonomia (BRASIL, 2013). No entanto, o discurso e o caráter das ofertas, que pressupõem a iniciativa do microempreendedor para auto capacitação, caracterizam o conceito de má fé institucional proposto por Souza (2009), onde o ponto de vista assumido para configurar uma oferta de serviço público é da classe que não irá se beneficiar dele, ignorando as diferenças de interpretação, acesso e competências que muitas vezes inviabilizam a plenitude dos resultados planejados. Para Salgado (2012) trata-se de um processo de individualização da responsabilidade pelo desemprego, que ao deixar de ser uma questão coletiva e complexa, desobriga governo e sociedade de trata-la.

Como política econômica, as limitações de enquadramento da personalidade jurídica impedem que impactos econômicos efetivos sejam gerados, para além do efeito de reduzir a taxa de desocupação reportada pelo governo (MTE, 2018; IBGE, 2007; Kon, 2012). Logo, há uma disfunção entre o objetivo aventado pelo poder público e o seu efeito social real.

Embora a alíquota de imposto seja de fato reduzida, ela funciona como um aumento de receita para o Estado, que passa a receber alguma contribuição de onde não vinha nada (Corseuil, Neri, \& Ulyssea, 2014; Salgado, 2012). Não há informações ou pesquisas que reportem efeitos reais do MEI em termos sociais ou econômicos. A princípio os maiores beneficiados são o Estado e as instituições financeiras que ampliam suas redes de microcrédito (Salgado, 2012). 
Se, por ventura, gerasse um empreendedorismo efetivo (SEBRAE, 2017; Ács et al., 2018), apenas aumentaria a competição interna no país, sem gerar negócios com escala para internacionalização. Além disso, não vem acompanhado com nenhuma medida que viabilize importações, logo não há esperança de que esses empreendedores movimentem a indústria de base ou agreguem beneficiamento efetivo a ao que de fato é produzido no país (Bacha, 2017; OCDE, 2018). Logo, o único efeito continua sendo laboral, sem grande expressividade na geração de novos postos de trabalho (SEBRAE, 2017), mesmo porque o enquadramento legal gera uma limitação para isso.

A concentração territorial do MEI em estados economicamente fortes, e com maior acesso a serviços públicos, educacionais e culturais, apenas reflete a desigualdade de capital humano que se materializa nas desigualdades sociais do território brasileiro (Barros, 2011; Gregorio \& Lee, 2002; Castello \& Domenech, 2002). E o fato de $22 \%$ dos MEI serem jovens pode ser um sintoma do agravamento da desigualdade social brasileira, por se tornar uma alternativa para a massa de jovens pouco qualificados e sem esperanças de ingressar no mercado de trabalho. Quanto mais precoce é o ingresso no mercado de trabalho e menor a escolaridade, pior é a tendência ao desemprego (OCDE, 2015; Ribeiro, 2009; Neri \& Costa, 2002).

O ciclo vicioso formado pela lógica que submete os investimentos sociais às políticas econômicas (Soares, 2015), nesse ponto se reforça: 1) as políticas sociais são limitadas pelas políticas econômicas; 2) as políticas econômicas são ineficientes para apresentarem uma mudança efetiva no posicionamento ou na produtividade da economia brasileira; 3) a desigualdade social se agrava sem instrumentos de transferência de renda e serviços públicos de qualidade; 4) o indivíduo de classe mais desfavorecida não encontra no mercado acesso a trabalho, renda, bens e serviços; 5) a economia não deslancha devido aos problemas acarretados pela desigualdade social, principalmente no que tange o capital humano.

A principal colaboração teórica deste estudo está no diálogo de dois temas pouco abordados em conjunto no contexto brasileiro: empreendedorismo e políticas públicas (Meneghetti, 2011). Sua implicação prática está em promover a discussão, e levantar questões não abordadas no discurso de incentivo ao cadastro no MEI. Por se tratar de um tema complexo e inter-relacionado com questões sensíveis, tais como emprego, desigualdade social, bem-estar social, economia, configura uma discussão de interesse publico que deve ser levada à diante.

Não se pode afirmar qual classe social mais aderiu ao MEI. Essa informação seria, inclusive, de grande utilidade para trabalhar os aspectos levantados neste estudo. Também não há como afirmar quem são os consumidores aos quais esses microempreendedores buscam atender. Seria interessante avaliar se há alguma relação de produção ou consumo vinculada à base da pirâmide econômica (Prahalad \& Hart, 2002; Yunus, 2010). Detalhamentos em relação as características, escala de comercialização e a sustentabilidade econômico-financeira dos negócios gerados sob essa personalidade jurídica também ajudariam a traçar um panorama mais bem delineado do fenômeno e seus efeitos (Ács et al., 2018; Ferreira et al., 2014; Shane, 2012). Identificar se a concentração de MEI colaborou com a estruturação de algum ecossistema empreendedor (Ács et al., 2018; Herrington \& Kew, 2016; Simatupang \& Schwab, 2015), e avaliar se de fato os MEIs se enquadram na classificação de empreendedores por necessidade, poderá ajudar a modelar políticas públicas mais efetivas (Summers, 2015; SEBRAE, 2016).

De forma resumida, é possível afirmar que o aumento da arrecadação fiscal não pode ser evidenciado, ficando como único efeito real a desobrigação do estado em relação às políticas de emprego e renda para os seus optantes. Entretanto, esses efeitos não estão sendo debatidos, e suas consequências não se encontram mapeadas.

Essa mercantilização do trabalho desafia a tese de Karl Polanyi (1977) de duplo movimento, que previa que os esforços para ampliar o mercado evocariam esforços para proteger os seres humanos, a natureza, e meios de produção das forças do mercado. Polanyi concentra sua crítica na transformação da terra, do trabalho e do capital em commodities, usando a insegurança econômica para motivar os seres humanos. O que ele teria dito da transformação de pessoas em unidades de negócio? 


\section{Referências}

Ács, Z. J., Szerb, L (2009). Global Entrepreneurship Index.

Ács, Z. J., Szerb, L., Autio, E., \& Lloyd, A. (2018). Global Entrepreneurship Index.

Bacha, E. (2017). Saída para a crise tem mão dupla. Estudos Avançados, 31(89), 23-27. doi:10.1590/s0103-40142017.31890003

Baron, R., \& Shane, S. (2006). Empreendedorismo: uma visão do processo. Editora Thomson Learning.

Barros, A. R. (2011). Desigualdades Regionais do Brasil. Rio de janeiro: Editora Elsevier.

BRASIL. Ministério do Desenvolvimento Social e Combate à Fome. (2005). Politica Nacional de Assistência Social e Norma Operacional Básica do SUAS. Brasília: MDS.

BRASIL. Ministério do Desenvolvimento Social e Combate à Fome. (2013). CapacitaSuas: Caderno 2. Proteção de Assistência Social, segurança de acesso a benefícios e serviços de qualidade. Brasília: MDS.

Bucci, M. P. D. (2006). O conceito de política pública em direito. Políticas públicas: reflexões sobre o conceito jurídico. São Paulo: Saraiva.

Caetano, G. (2015). Pobreza y desigualdad en América Latina (1980-2014). Diario del País - Contrapuntos. Recuperado de http://blogs.elpais.com/contrapuntos/2015/03/pobreza-y-desigualdad-en-americalatina1980-2014.html.

Cappelli, P. (1999). The new deal at work. Boston: Harvard Business School Press.

Castello, A., \& Domenech, R. (2002). Human capital inequality and economic growth: Some new evidence. Economic Journal, 112(478), C187-C200. doi: 10.1111/1468-0297.00024

Chowdhury, R. S. (2013). Wealth inequality, entrepreneurship and industrialization. Journal of Economics/ Zeitschrift Fur Nationalokonomie, 108(1), 81-102. doi: 10.1007/s00712-012-0268-6

Corseuil, C. H. L., Neri, M. C., \& Ulyssea, G. (2014). Uma análise exploratória dos efeitos da politica de formalização dos microempreendedores individuais, Texto para Discussão, Instituto de Pesquisa Econômica Aplicada (IPEA), No. 1939.

Costa, A. M. D., Barros, D. F., \& Carvalho, J. L. F. (2011). A dimensão histórica dos discursos acerca do empreendedor e do empreendedorismo. RAC-Revista de Administração Contemporânea, 15(2).

Costa, A. D. S. M., \& Saraiva, L. A. (2012). Hegemonic discourses on entrepreneurship as an ideological mechanism for the reproduction of capital. Organization, 19(5), 587-614.

Frey, K. (2000). Políticas públicas: um debate conceitual e reflexões referentes à prática da análise de políticas públicas no Brasil. Planejamento e políticas públicas, 21, 211-259.

Gil, Antonio Carlos.(2008). Como elaborar projetos de pesquisa. São Paulo: Editora Atlas

Gregorio, J. De, \& Lee, J. W. (2002). Education and Income Inequality: New Evidence From Cross-Country Data. Review of Income and Wealth. doi: 10.1111/1475-4991.00060

Hayward, M. L. A., Shepherd, D. A., Griffin, D., Cromie, S., \& Callaghan, A. (2006). Hubris Theory of Entrepreneurship. Management Science, 4(2), 65-71, 2006.

Herrington, M.; Kew, P. (2016) Global Entrepreneurship Monitor 2016/2017. Crise Global Entrepreneurship Monitor, 1-180. https://doi.org/10.1017/CBO9781107415324.004

IBGE - Instituto Brasileiro de Geografia e Estatística. (2007). Série Relatórios Metodológicos: Pesquisa Mensal de Emprego. 23. $2^{\mathrm{a}}$ edição. Rio de Janeiro 
IBGE - Instituto Brasileiro de Geografia e estatística. (2017). Pesquisa Nacional por Amostra de Domicílios $[P N A D]$. $\quad 1^{\circ}$ trimestre. Recuperado de https://www.ibge.gov.br/estatisticasnovoportal/sociais/trabalho/9173-pesquisa-nacional-por-amostra-de-domicilios-continuatrimestral.html?edicao $=20106 \& \mathrm{t}=$ destaques em19/03/2017.

IBGE - Instituto Brasileiro de Geografia e Estatística. (2017). Estatísticas de empreendedorismo: 2015. Rio de Janeiro. ISSN 1679-480X.

Ibarra-Colado, E. (2006). Organization studies and epistemic coloniality in Latin America: thinking otherness from the margins. Organization, 13(4), 463-488.

Kon, A. (2012). Pleno emprego no Brasil: interpretando os conceitos e indicadores. Revista Economia \& Tecnologia, 8(2), 5-22.

Maloney, W. (2004). Informality revisited. World development, 32, 1159-1178.

Meneghetti, F. K. (2011). Documentos e Debates O que é um Ensaio-Teórico? What is a Theoretical Essay? RAC, 15(2), 320-332.

MTE - Ministério do trabalho e emprego. (2015). Relação Anual de Informações Sociais [RAIS]. Recuperado de http://pdet.mte.gov.br/rais?view=default.

MTE - Ministério do trabalho e emprego. (2018). Portal do Empreendedor - MEI. Recuperado de http://www.portaldoempreendedor.gov.br/menu-rodape/sobre-o-portal-1 .

Nassif, V. M. J., Ghobril, A. N., \& Amaral, D. J. (2009). Empreendedorismo por Necessidade: O Desemprego como Impulsionador da Criação de Novos Negócios no Brasil. Pensamento \& Realidade, 24(1), 143-168.

Neri, M., \& Costa, D. (2002). O tempo das crianças. Ensaios Econômicos, 468. Recuperado de http://bibliotecadigital.fgv.br/dspace/handle/10438/532

OCDE - Organização para a Cooperação e Desenvolvimento Económico. (2015). Relatórios Econômicos OCDE: Brasil. Recuperado de http://www.oecd.org/eco/surveys/Brasil-2015-resumo.pdf

OCDE - Organização para a Cooperação e Desenvolvimento Económico. (2018). Relatórios Econômicos OCDE: Brasil. Recuperado de http://www.oecd.org/eco/surveys/Brazil-2018-OECD-economicsurvey-overview-Portuguese.pdf

Piketty, T. (2015). A Economia da Desigualdade. André Telles (Trad.). Rio de Janeiro: Editora Intrínseca.

Polanyi, K. (1977). A nossa obsoleta mentalidade mercantil. Revista Trimestral de História das Ideias, 1, 720. Porto: Portugal.

Ribeiro, R. (2009). Juventude(s): desocupadas. Nova Economia, 19(3), 475-506. doi: 10.1590/S010363512009000300004

Salgado, J. (2012). Corpo miserável, espírito empreendedor: empreendedorismo, pobreza e desemprego no Brasil. Revista da Faculdade de Serviço Social da Universidade do Estado do Rio de Janeiro, 10(30), 129-147.

Santana, V. C. (2016). Pobreza, exclusão social e territorialidades. In V Congresso em Desenvolvimento Social, Montes Claros - MG.

Santos, B. S. (2002). Reinventar a democracia. Fundação Mário Soares. Lisboa: Gradiva Publicações LTDA.

Sarfati, G. (2013). Estágios de desenvolvimento econômico e políticas públicas de empreendedorismo e de micro, pequenas e médias empresas (MPMEs) em perspectiva comparada: os casos do Brasil, do Canadá, do Chile, da Irlanda e da Itália. Revista de Administração Pública, 47(1), 25-48. 
Sette, R. S., Boava, D. L. T., \& Macedo, F. M. F. (2012). Contribuições do Ensaio Teórico para os Estudos Organizacionais. In VII Encontro de Estudos Organizacionais da ANPAD - eNeo, Curitiba-PR.

Summers, D. (2015). The Economic Impact of Entrepreneurship: setting realistics expectations. Academy of Entrepreneurship Journal, 21(2), 99-108.

SEBRAE - Serviço Brasileiro de Apoio às Micro e Pequena Empresas. (2016). Taxa de sobrevivência das empresas no Brasil.

SEBRAE - Serviço Brasileiro de Apoio às Micro e Pequenas Empresas. (2017). Relatório Especial: O empreendedorismo e o Mercado de Trabalho. Recuperado de

https://m.sebrae.com.br/sites/PortalSebrae/estudos pesquisas/relatorio-especial-o

empreendedorismo-e-O-mercado-detrabalhodetalhe52,5cdfda0e84ebe510VgnVCM1000004c00210aRCRD

SEBRAE - Serviço Brasileiro de Apoio às Micro e Pequena Empresas. (2018). Tire suas dúvidas sobre o MEI (Microempreendedor Individual). Recuperado de

http://www.sebrae.com.br/sites/PortalSebrae/sebraeaz/tire-suas-duvidas-sobre-o-meimicroempreendedor-individual,e31c13074c0a3410VgnVCM1000003b74010aRCRD

Shane, S., \& Venkataraman, S. (2000). The promise of entrepreneurship as a field of research. Academy of Management Review, 25(1), 217-226.

Shane, S. (2012). Reflections on the 2010 AMR decade award: delivering on the promise of entrepreneurship as a field of research. Academy of Management Review, 37(1), 10-20.

Simatupang, T. M., Schwab, A., \& Lantu, D. C. (2015). Introduction: Building Sustainable

Entrepreneurship Ecosystems. Editorial, International Journal of Entrepreneurship and Small

Business, 26(4), 389-398.

Soares, L. T. (2015). Politica Social, crisis económica y ajuste fiscal: los dilemas persistentes. In Conferencia CLACSO Medellín; panel 7 - Retos de la política social en América Latina en tiempos de freno económico (II). FLACSO - Brasil

Solano, C. B. (2015). La encrucijada de la desigualdad y la politica social en América Latina. Diario El País - Contrapuntos. Recuperado de http://blogs.elpais.com/contrapuntos/2015/04/la-encrucijada-de-ladesigualdad-y-lapolitica-social-en-america-latina.html

Souza, J. (2009). Ralé Brasileira - quem é e como vive. Belo Horizonte: Editora UFMG.

Stiglitz, J. E. (2012). El precio de la desigualdad Estados Unidos ya no puede considerarse la tierra de oportunidades que alguna vez fue. Diario El País. (C) Project Syndicate. Recuperado de http://economia.elpais.com/economia/2012/06/15/actualidad/1339754056_983920.html

Yunus, M. (2010). Criando um Negócio Social. Rio de Janeiro: Editora Campos.

Wanderley, S., \& Barros, A. (2018). Decoloniality, geopolitics of knowledge and historic turn: towards a Latin American agenda. Management \& Organizational History, 1-19.

Zouain, D. M., Oliveira, F. B. D., \& Barone, F. M. (2007). Construindo o perfil do jovem empreendedor brasileiro: relevância para a formulação e implementação de políticas de estímulo ao empreendedorismo. Revista de Administração Pública, 41(4), 797-807. 